\title{
El Estado republicano peruano y la expansión jurisdiccional del método lancasteriano en las poblaciones próximas a Lima, 1821-1840
}

Recibido: 16/11/2017

Aprobado: 01/12/2017
Juan Carlos Huaraj Acuña

Universidad Nacional Mayor de San Marcos

<jhuaraja@unmsm.edu.pe >

\section{RESUMEN}

La instrucción pública desde la instalación de la República misma, fue auspiciada por el propio Estado. Lo afirmado se comprueba meridianamente a través de los diversos decretos supremos y documentación legislativa a ella referidas. Inicialmente, bajo el patrocinio institucional de la Beneficencia Pública, así como de los Prefectos. En sus crepusculares funciones educativas, el Estado se vio apoyado por las instituciones clericales, como las parroquias y diócesis locales. El Colegio Central (o Normal) Lancasteriano, representó una creación política directa del período histórico del Protectorado. La precitada institución educativa, bajo la dirección del Pbro. José Francisco Navarrete, alcanzó no solo la venia y buena pro por parte del Supremo Gobierno durante sucesivos gobiernos, sino que ello representó abiertamente y sin duda alguna, la alianza política inicial entre la República peruana y la Iglesia, en este orden.

Palabras clave: Educación lancasteriana, Joseph Lancaster, instrucción primeras letras, instrucción pública, Colegio lancasteriano de Lima, Diego Thompson, José Francisco Navarrete, José de San Martín, Bolívar, Colegio Normal, educación siglo XIX, republicana peruana, educación republicana, Canta, Callao, Bellavista, Huacho, Yauyos.

\section{The Peruvian republican State and the jurisdictional expansion of the Lancasterian method in the towns near Lima, 1821-1840}

\begin{abstract}
The public instruction since the installation of the Republic itself, was sponsored by the State itself. The affirmed is verified in detail through the various supreme decrees and legislative documentation referred to it. Initially, under the institutional sponsorship of the Public Beneficence, as well as of the regionals Prefects. In its crepuscular educational functions, the State was supported by clerical institutions, such as local parishes and dioceses. The Central (or Normal) Lancasterian College, represented a direct political creation of the historical period of the Protectorate. The aforementioned educational institution, under the direction of Pbro. José Francisco Navarrete, reached not only the goodwill and goodwill of the Supreme Government during successive governments, but that represented openly and without any doubt, the initial political alliance between the Peruvian Republic and the Church, in that order.
\end{abstract}

KeYwords: Lancastrian education, Joseph Lancaster, instruction first letters, public education, lancasterian College of Lima, Diego Thompson, Jose Francisco Navarrete, Jose de San Martin, Bolivar, Normal College, education nineteenth century, Peruvian republican, republican education, Sing, Callao, Bellavista, Huacho, Yauyos. 


\section{Breve introducción: relaciones entre el Estado y la educación}

D esde su creación el Estado republicano afirmó su existencia a través de distintos acuerdos políticos frente a las diversas fuerzas que la sopesaron e hicieron posible su viabilidad y continuación en el tiempo. Hoy en día el Estado lo sigue haciendo, aunque bajo un escenario social y económico distinto a lo que fue el mismo durante las épocas de la década de 1950, a principios de siglo durante la denominada República Aristocrática, e inclusive durante el siglo xIx. No en vano, hoy ya cercanos al bicentenario, existe públicamente una organización bajo la nominación de Acuerdo Nacional, que incluye y propone las propuestas especializadas en distintos ámbitos del desarrollo nacional, en nuestro caso particular, desde la educación (2016). La educación es un fenómeno social y tangible sin duda alguna. Esta afirmación representa una clara referencia a los postulados científicos de Emilio Durkheim. Cada sociedad elabora e interviene en la construcción, o supresión, de sus propias redes de interacción social (Durkheim, 1975). La educación se entiende así como una serie de herencias y continuidades, particulares de las tradiciones sociales, eminentemente colectivas, y vivientes de la sociedad en donde se desarrolla. En la primera parte de nuestra tesis de maestría, afirmo categóricamente que fue el Estado tardío colonial decimonónico, el principal antecedente histórico y social, de la formación del Estado republicano (Huaraj, 2017)

\section{La instrucción de primeras letras en la ciudad de Lima, 1820-1840}

La instrucción lancasteriana en el Perú se inició en Lima, con la llegada de Diego Thompson al Perú, en 1822. La presente investigación representa la continuación del referido proceso histórico, así como la progresiva expansión del método pedagógico lancasteriano al interior del país, en este caso, en dirección a las ciudades y pueblos andinos de las afueras de la ciudad capital. Para el año de 1826, dentro el organigrama del Estado, ya se encontró oficializada la Dirección General de Educación. Aunque sus alcances y limitaciones jurídicas y jurisdicciones no estaban definidos bajo escrudińado reglamento, pues el mismo no será redactado sino hasta mediados del siglo XIX, durante el segundo gobierno del Presidente Ramón Castilla.

Para 1826, últimos meses del Bolivarianismo en el Perú, el responsable del referido despacho público fue Nicolás de Piérola — padre de quien fuera Presidente del Perú en dos ocasiones-. Su autoridad la debió ejercer en diálogo constante con otras autoridades, como la del Prefecto de Lima, quien, a su vez, elevaba las sugerencias y reclamos del ramo educativo al Ministerio del Estado, a la vez que refrendaba (o rechazaba finalmente) las resoluciones respectivas. Ello también nos alcanza un indicador sobre la enorme dependencia de la diversidad de ministerios y encargos públicos frente al Poder ejecutivo, ello durante gran parte del siglo. Y solo algunos documentos llegarían a ser firmados por el Presidente del Supremo Gobierno, muy pocos. Volviendo a Lima, en 1826, Nicolás de Piérola expuso la necesidad de crear más Escuelas de Primeras Letras, aparte de las que ya existían en Chorrillos y Pachacámac. Propuso como centros poblados a ser favorecidos: los pueblos balnearios de Ancón, Miraflores, Chorrillos, y Lurín; así como los pueblos de composición agrícola como: Carabayllo, Magdalena, Surco, Cieneguilla y Ate. Cabe precisar que ello no significa (necesariamente) que en dicho lugares no existiesen escuelas, pero las mismas se hallaron con evidente precariedad en sus estructuras, maestros no constantes en su asistencia, y de ninguna manera bajo la metodología lancasteriana.

El prefecto aprobó la erección de las mismas, pero (lamentablemente) tampoco nos consta que hayan sido finalmente dispuestas hacia la población misma beneficiaria. La problemática que atravesaban estas Escuelas, sobre todo bajo el ámbito pedagógico, fue realmente dramática, a saber: "Que los maestros son hombres sin ninguna disposición y pagados por un real semanal que el padre de cada párvulo aporta. Se pide que el financiamiento sea obtenido de los fondos de los tambos y de las Cajas de Censos de Indios, para dotar a los maestros» (AGNP; Fondo de Instrucción; 1826; Leg. 175).

Fueron estas duras frases con las que, hoy, podemos tener hoy una remota idea de la pésima calidad de educación en primeras letras que recibieron los niños en los pueblos y comunidades fuera de la gran ciudad capital. Actualmente es posible observar historiadores de la educación que desconocen totalmente la muy tenue, o nula, relación entre la emisión de las leyes 
desde el gobierno, o permisos municipales para licencia de funcionamiento, y su verdadera ejecución. Y con tales carencias pretenden generalizar y re-construir una historia de posición ciudadana, cuando la gran mayoría de la población — siquiera la circundante a la gran ciudad - nunca recibió los beneficios de la instrucción pública. Una de las pocas instituciones orientadas, por su cuenta y sostenimiento, a la instrucción pública, fueron las parroquias católicas, tanto de ciudades como rurales, aunque su finalidad fuera la de evangelizar y catequizar, evidentemente. Pero el Estado republicano empezó también a asumir progresivamente sus funciones públicas educativas. No se desentendió del mismo.

En forma intercalada, los primeros Directores Generales fueron el Pbro. José Francisco Navarrete Sánchez, y el mencionado Nicolás de Piérola, hombres, que se abocaron a la organización de las escuelas primarias, por la honorabilísima razón de su vocación hacia la población más vulnerable, los niños y niñas. Hubo también otros Directores, pero ello respondió al vaivén político que vivió nuestra temprana República. En ello, los precitados directores, contaron con la aún tenue cantidad de maestros lancasterianos egresados de las nacientes escuelas normales. Aunque también debían tomar en cuenta individuos dedicados por necesidad a la enseńanza primaria, con poca o ninguna disposición para ella. De ello ya en 1826, las autoridades de prefecturas y municipios recomendaron a quienes desearen ser maestros preceptores de primeras letras, el instruirse en el método lancasteriano. Aunque bien sabemos que ello sería más una buena intención, que una realidad palpable.

El método lancasteriano fue tomado como un método para gente pobre, ello era la percepción tanto de las autoridades republicanas, como de la población medianamente alfabetizada. Los documentos oficiales, en diversas oportunidades así lo hicieron saber:

A asistir a la Escuela Normal Lancasteriana de esta capital el tiempo de tres meses continuos, a instruirse en este ingenioso método principalmente inventado para la gente pobre y del campo (AGNP; Fondo de Instrucción; 1826; Leg. 175)

Progresivamente el método lancasteriano calaría principalmente sobre la población urbana, luego lo sería ante la rural.

\section{Instrucción de primeras letras en las provincias de Lima: Yauyos y Pativilca, 1828-1837}

\subsection{Las primeras letras en Yauyos}

En 1828, el prefecto Ramón Soto, hizo notorio al Superior Gobierno el estado de miseria en el que vivían los vecinos de esta provincia ${ }^{1}$, cuyas instituciones como el cabildo local, así como la Junta Departamental, no pudieron invertir siquiera en el pago de una escuela de primeras letras. $\mathrm{O}$ en todo caso, no fue de su interés hacerlo. Describe su pobreza al nivel inclusive de ni siquiera proveerse de alimentos propios, sino deben comprarlo de otras provincias como Jauja y Cańete. Así mismo, Soto hace observar que toda la región está compuesta por indios: "Toda la provincia es habitada por la clase indígena, mitaya, y que no se haya en actitud de remitir a sus hijos a la capital» (AGNP; Fondo de Instrucción; 1828; Leg. 175).

Tras describir las precarias situaciones educativas y sociales, las pequeñas comunidades, aquellas de composición mayoritariamente indígena y mestiza, propiciaron una iniciativa particular: contratar maestros lancasterianos. Sin embargo, y otra vez, las voluntades populares se vieron frente a una dura realidad, las provincias solo podían pagar cuotas entre 100 a 150 pesos anuales para dichos maestros, cuanto mucho. Esta modesta cantidad solo les alcanzó para contratar hombres de "pocas suertes y luces, y, así lo más que se consigue es que aprendan a rezar y conocer mal el abecedario" (Ídem.). Si lo comparamos con los 10 pesos mensuales que se pagaba a un instructor privado para la enseñanza en la ciudad, solo por escritura y aritmética, además de la distancia y el tiempo, y por supuesto el número de estudiantes a quienes se les podía dedicar algunas horas (o días) de trabajo extra, pues no había comparación. Simplemente fue abismal la diferencia entre los maestros quienes impartían sus lecciones de primeras letras en provincias, y los que ofrecían sus servicios en las principales ciudades. Es más, su estipendio dependía directamente de la comunidad de indios, pues sí la misma era solícito a facilitar integrantes más jóvenes para la multiplicación de la instrucción, pues la misma tenía mejores oportunidades. Y ello, políticamente significaba que relaciones de las autoridades locales para con la Junta de Principales, así como frente a los prefectos, contuvieron

$1 \quad$ Leg. 175. S/ N. Enero de 1828. 
MAPA ACTUAL DE LA PROVINCIA DE YAUYOS*



Fuente: Google Maps. Alphabet INC. DR. 2016.

* Nótese la importancia estratégica de Yauyos, como ruta obligada de Lima hacia el centro del país, ciudades como Huancayo, y los fructíferos valles de Concepción, San Ramón, Tarma, entre otros. Asimismo, paso importante hacia los Andes del Sur, como Huancavelica, y de allí a las grandes ciudades andinas, como Huancavelica, y su neurálgico centro minero. bajo el cargo de infracciones por procedimientos anticonstitucionales (S/A; 1833; P. 03, 04) ${ }^{3}$. No podemos afirmar ahora si a este nivel de funcionarios-militares se encontraban más tiempo o en la región geográfica a la que representaban, o si se hallaban más tiempo en la ciudad de Lima. En aquel manifiesto, Yauyos también abogó por la aplicación de la pedagogía lancasteriana en sus escuelas (a pesar de contar con profesores rústicos). Posteriormente, para 1837, registraron aproximadamente 651 alumnos de primeras letras (Carrasco; 1840; p. 39). la suficiente sintonía para ejecutarlo. Y ello solo era logrado por las ciudades cabeceras de pueblos... y no todos los pueblos bajo aquella denominación, solo aquellos cuyo tránsito de trajinantes y comerciantes era importante.

Entre 1833 y 1835, se halló como representante de la provincia de Santo Domingo de Yauyos (a poco más de 290 km., de Lima), ante la Muy Honorable Junta Departamental de Lima, Nero Forcelledo, aunque en el registro de 1833, el mismo Forcelledo ${ }^{2}$ se registró específicamente como miembro titular de dicha Junta. Este personaje tuvo un interesante recorrido político durante la temprana república. Interesante, pues muchas veces se cree que la principales figuras políticas del Perú decimonónico, solo eran aquellos provenientes o de las grandes ciudades del país, o hijos de grandes hacendados o mineros. Con Forcelledo se puede observar que la procedencia de los operadores políticos podía surgir desde los pueblos del interior de las ciudades andinas.

En la reunión del veintidós (22) de agosto, el registro de las Actas de los Colegios Electorales locales de aquellas provincia, se eligió a uno de los representantes de la doctrina de Laraos. Y en 1833, que en conjunto, toda la provincia de Yauyos firmó un público manifiesto contra el prefecto nombrado por Gamarra,

2 ¿Tendría parentesco sanguíneo con quien fuera Presidente de la Cámara de Diputados del Perú entre 1852 y 1853, Francisco Forcelledo?

\subsection{Las primeras letras en Pativilca}

Hasta aquí, podemos afirmar que a pesar de la importancia estratégica de algunos pueblos y ciudades, el alcance del gobierno central en diversas zonas de altura, aún no recibían los beneficios de la instrucción lancasteriana. En Pativilca, a 196 kilómetros de la ciudad capital, para la época se encontraba dentro de la provincia de Chancay. Recordemos su importancia geográfica estratégica: fue el espacio apropiado para el estacionamiento de las tropas militares, del Generalísimo San Martín. No era una ciudad capital de provincia, aunque sí un obligado lugar de tránsito hacia lugares como Huaricanga, Recuay y Huaráz, la representatividad del Estado en estos lugares era escaso. Aquí la institución de mayor influencia social y política sería el párroco. Teniendo como ciudad más cercana a Huacho, allí, el párroco Manuel Suces expresó públicamente construir una escuela de Primeras Letras y latinidad, en beneficio de los nińos y jóvenes tanto de la ciudad, como de aquellos pueblos de cabecera cercanos. En último término indicaba la presencia de

3 Era evidente que la elección de Forcelledo, debía estar en común acuerdo con el documento que se iba a firmar contra el Prefecto de la ciudad. Actualmente no se ha estudiado muy bien el papel de las Juntas Departamentales durante el siglo diecinueve, jserían las nuevas, y más abiertas, formas de participación de las ciudades y pueblos al interior del país, posterior a la clausura de los Alcaldes de indios coloniales? 
alguien que pudiese enseñar lengua castellana, y, en lo posible, enseñanzas superiores al de las Primeras Letras.

Para el sostenimiento de la propia escuela propuso que el Intendente obligase a los mandaderos (aquellos campesinos que mandados a pastear ganado) a pagar el $01 \%$ por usar los pastos de aquel distrito (AGNP; Real Justicia; 1827; Leg. 75). La razón que esgrima el cura es con el justo objeto de propagar en los jóvenes la ilustración que se desea. Claro, también se podía exigir los mismo a los comerciantes, pero, y seguramente, su gremio local tuvo mayor presencia política que el de los primeros mencionados. Aquí también resulta que la solicitud de fundación de una escuela primaria no parte de una propuesta del Estado o alguno de sus representantes, es una gestión iniciada por el párroco del lugar, y aprobada por la comunidad, y elevada, por si fuera poco, a la junta departamental, quien ejerció la función política de tramitar y elevar el reclamo hacia las instancias donde debía ser recibido: las autoridades del poder ejecutivo, en la ciudad capital.

En dicho informe se lee que sus niños y párvulos «se hallan en el mayor abandono, tanto en los rudimentos de fe, cuanto imbuidos en la ignorancia de las primeras letras» (Ídem.). El monto para pagar los servicios del preceptor, cuya dependencia sería el del Procurador síndico de la región, era insuficiente. El ánimo y entusiasmo empezaban a ser factores de conjunción de aportes y voluntades. Progresivamente se fueron

\section{MAPA ACTUAL DE LA RUTA PATIVILCA - HUACHO - LIMA}

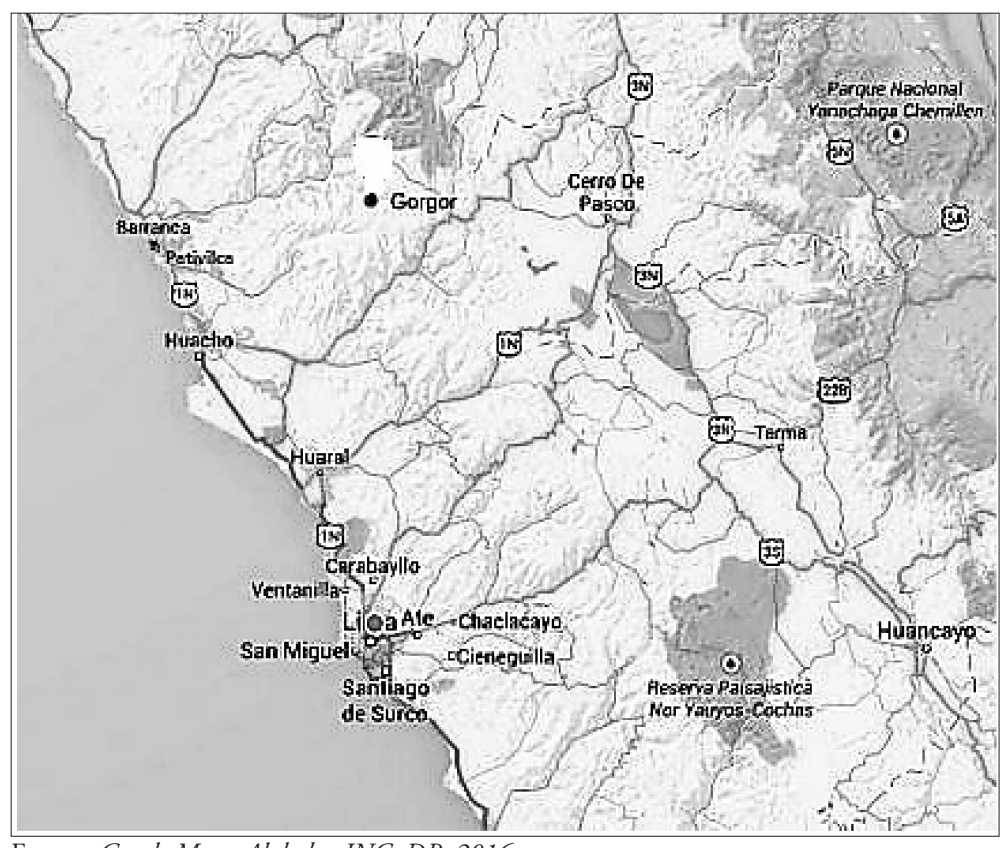

aunando los otros gremios locales. Uno de los representantes de la ciudad, Luis Salinas, propuso: «[...] El cobro de un real a los ganaderos de las alturas que pasen por el pueblo, medio real por cabeza de carnero; y a los camaleros que dan abasto al pueblo, $1 / 2$ real por cabeza» (AGNP; Real Justicia, Ídem.).

La propuesta llegó hasta el mismo Gobierno, y fue aprobado por el ministro Francisco Javier Mariátegui en septiembre de 1827, en las mismas condiciones solicitadas. Podemos inducir que el gobierno estaba llano a las propuestas educativas, claro mientras las mismas no solicitasen subvención estatal del mismo, sus prioridades son otras, como inestables. Otros centros poblados, como Lurín y el Callao empiezan a solicitar jóvenes de la Escuela Lancasteriana a instruirnos con sus conocimientos... Pero las condiciones para estos primeros preceptores, aún fueron adversas, sobre todo en el tema de los pagos por servicios prestados.

\subsection{Instrucción de primeras letras en Canta, 1826-1852}

La Ciudad de Lima está rodeadas de montañas y cerros, un recuerdo geográfico potente de su pertenencia a los estribos de la cordillera andina. A pocos kilómetros frente al mar, los Andes le enrostran al limeño su enorme e intimidante presencia en su diario viaje y trajinar. Y de ello bien lo afirmarían tanto el limeño colonial orgulloso, soberbio, del siglo diecisiete (s. XVII), como del timorato e medroso habitante durante los duros tiempos por las guerras de la independencia. Y era entendible, las levas de los ejércitos de los diversos caudillos así los predispusieron.

Desde los inicios mismos de la República, la ciudad de Canta tenía como una de sus presencias públicas más representativas, a sus curas, párrocos y doctrineros. Desde los tiempos coloniales. Dentro de los miembros de la curia eclesiástica capitalina, todos los pueblos de Canta contaron con la presencia de representantes de la Iglesia, desde el comienzo mismo de la evangelización en el mundo andino, durante el siglo dieciséis (León 2008, p. 32), la labor de las doctrinas aún continuaban en funciones. El nombre de los presbíteros encargados de la administración de las parroquias en 
todas las provincias canteñas ${ }^{4}$ (Piérola; 1827; P. 54), entre 1827 y 1828 , fueron a continuación:

Párroco de Huamantanga, a Manuel Gárate. Este presbítero poseyó también la máxima representatividad de la jurisdicción ante el Cabildo Eclesiástico limeño, al poseer el encargo de Vicario y juez eclesiástico de todo Canta. Esta villa era la ruta obligada hacia Pacaraos.

- Párroco de Canta, José Mier, junto con su coadjutor, Mariano Alzamora.

- Párroco de Pomacochas, Domingo Alcarráz, junto con su coadjutor, Tomás Ávalos Chauca.

- De San Buenaventura, a Francisco de la Banda.

- De Atavillos Altos, a José Toribio Gonzáles.

- De Atavillos Bajos, a Francisco Valdiviezo.

- En Pacaraos, bajo la designación de interino, a Manuel Bustamante. Ésta es una de las zonas más alejadas de la capital de provincia.

- De Arahuay, a Manuel Carrillo.

- De Lampián, a José María Rosas.

Como acostumbraron a redactarlos los propios funcionarios públicos de la época, la división jurisdiccional eclesiástica, fue también la división que iría tomando el Estado, en pos de organizar apropiadamente sus provincias y distritos. El intendente de la provincia de Canta a fines de la década de 1820, fue Manuel Ramos. Ante el paso inexorable del tiempo, ya en la década siguiente, Canta empezó a figurar en los calendarios con u mayor número de funcionarios públicos, como correspondía a una de las ocho provincias del Departamento de Lima. Aunque, extrañamente, no poseyó representantes en la Convención Nacional convocada en 1832, e instalada en diciembre del año siguiente. Sin embargo, sí poseyó representantes en la Cámara de Diputados, figurando (otra vez) el Pbro. Manuel Gárate como su diputado electo (PAREDES; 1821; P. 104, 105). Reiteramos, aún era demasiado temprano en la organización política de la joven república, el exigir que sus diputados reconozcan (o al menos visiten) las geografías a las cuáles, se supone, representan. Pero en el caso específico de Canta, el antiguo Párroco de Huamantanga, fue en dicho año, representante no solo de su investidura eclesial, también del poder político. La provincia de Canta se dividió en diez (10) distritos, a saber: Araguay, Atavillos Altos, Atavillos Bajos,

4 PIÉROLA. F., Nicolás. "Calendario y guía de forasteros de Lima, para el ańo bisiesto de 1828». Imprenta de la Instrucción primaria. Por Juan Ross. Lima-Perú, 1827
Canta, Huallay, Huamantanga, Lampián, Pacaraos, Pomacocha, y San Buenaventura. Solo un pueblo más a los administrados por la curia eclesiástica limeña.

Por su posición estratégica geográfica, el ejército hizo también presencia aquí. Poseía una guarnición militar, aunque relegado a estamentos menores e inferiores de la jerarquía militar. Dependiente del Prefecto de Lima, en dicho año se halló como Subprefecto de la ciudad al Sargento Mayor, Martín Magán. Inclusive, contó también con un regimiento de caballería, el año precitado a cargo del Coronel José Campo. A modo de pronta reflexión, un destacamento militar, con guarniciones de soldados, así como de dragones no era de poca representatividad dentro de la región. En Canta, como en los otros tantos pueblos de cabecera republicanos ubicados a lo largo de la cordillera andina, los representantes del Estado iban haciendo presencia, progresivamente, al menos hasta donde se extiende temporalmente nuestra investigación propuesta, a saber:

- Los párrocos,

- La jerarquía menor e intermedia del ejército,

- Los funcionarios de correos,

- Los representantes de las aduanas,

- Los miembros de las Juntas Departamentales, entre otros.

Y a partir de la década de 1830, empezaron a hacerse presentes los colegios de instrucción primaria, bajo metodología lancasteriana. Como ya lo anotamos líneas atrás, uno de los medios representativos que tenían contrapeso político al momento de realizar sus exigencias al gobierno central, eran las Juntas Departamentales, y era a través de ellos, tal vez la única, posibilidad de exigir al Gobierno Central la pronta presencia de los maestros de dicha instrucción. Semejante a los contextos sociales y políticos de Pativilca o Huaura, estos pueblos no poseían personas idóneas para la formación de sus niños en las Primeras Letras. Entre las propuestas políticas elevadas al poder político limeño, se halló que los sueldos de los maestros que trabajarían en dichos pueblos, iban a ser costeados por las propias comunidades campesinas, ello la novedad más interesante de resaltar. Pueblos como Canta, Huamantanga o San Buenaventura elevaron al Supremo Gobierno, que serían ellas mismas quienes solventarían la instrucción de sus menores hijos. Pero la realidad, otra vez, fue muy dura para dichos pobladores, pues aquellos instructores que fungieron sus 
MAPA ACTUAL DE LA PROVINCIA DE CANTA**

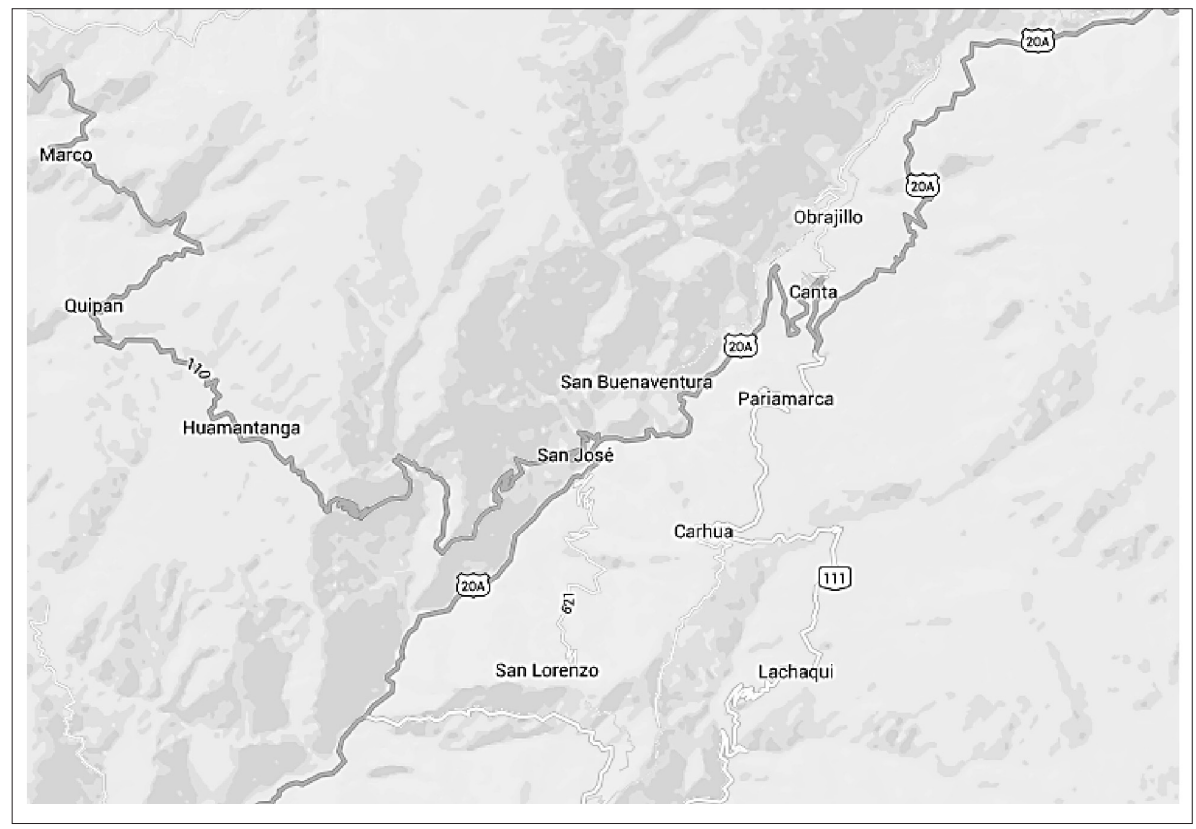

Fuente: Google Maps. Alphabet INC. DR. 2016.

** Nótese la importancia estratégica de Huamantanga, como ruta obligada hacia las Minas de Cerro de Pasco, así como al centro del país, y otras ciudades como Huánuco, más al norte; o a Paucartambo, ya entrando en los linderos de la Prefectura de Cusco; como también hacia los feraces valles amazónicos de Tarma, San Ramón y la Merced.

funciones como docentes, en realidad fueron personas sin mayor exigencia que la de saber leer y escribir. En los informes que enviaron a la capital, describieron a sus instructores locales en los términos mencionados: «brutos para la instrucción» (Ídem.). Pero no quedaban otras opciones, y debían continuar con los mismos.

¿Pudieron cambiarse estas condiciones en las provincias aledañas a la ciudad de Lima? Por ejemplo, ya en 1837, el director general, José Francisco Navarrete envió al Secretario de Instrucción - y quien anteriormente ejerció el cargo de director generalNicolás de Piérola ${ }^{5}$, a que supervisase e informase a la Escuela Central la situación de la instrucción primaria en Canta. Piérola halló el siguiente penoso resultado ${ }^{6}$ :

\begin{tabular}{|c|c|c|c|c|}
\hline Pueblos & Escuelas & Método & $\begin{array}{c}\boldsymbol{N .}^{\circ} \text { de } \\
\text { alumnos }\end{array}$ & Preceptores \\
\hline 50 & $\begin{array}{c}\text { Precarias, } \\
\text { pagadas por } \\
\text { sus padres. }\end{array}$ & Incierto. & Contingentes & Contingentes \\
\hline
\end{tabular}

5 Y ello era otra muestra evidente más de su desprendimiento y celo por su función que le valió la posteridad, llevar la instrucción lancasteriana a todos los pueblos hacia donde sus fuerzas pudieran llevarlos. A pesar de lo que afirman por escrito algunos colegas críticos contemporáneos, en torno a su epónima figura.

$6 \quad$ Leg. 175. S/ N. Abril de 1837.
Lancasteriana, poco menos de una década. Sin embargo, los maestros lancasterianos egresados de la Central, buscaron generalmente a enseñar en espacios cercanos a las grandes ciudades como Lima, poblados como Magdalena o Chorrillos, el Callao, entre otras jurisdicciones. A continuaciones un cuadro sobre aquello que la pedagogía contemporánea denominaría de aptitudes pedagógicas, a nuestro criterio:

ESQUEMA DE APTITUDES PEDAGÓGICAS
\begin{tabular}{|c|c|c|c|}
\hline $\begin{array}{c}\text { Instrucción } \\
\text { literaria }\end{array}$ & Cualidades & Rentas & Preceptores \\
\hline Incierta & $\begin{array}{c}\text { Precarias, pagadas } \\
\text { por sus padres. }\end{array}$ & Incierto. & Contingentes \\
\hline
\end{tabular}

Fueron los propios pueblos de Canta quienes empezaron a observar la necesidad de una mejor implementación de la formación pública, algunos de ellos dotaron personalmente de una cantidad de pesos un poco más atractiva para mejores maestros, pero aun así resultaba insuficiente:

- La Hacienda El Molino, que dotó de 150 pesos [anuales] a su escuela de Primeras Letras y tiene 40 niños. Ello representó menos de trece pesos (13 ps.) mensuales. 
- Hacienda La Estancia, que dotó de 200 pesos a su escuela.

- La comunidad de Obrajillo, que dotó de 100 pesos a su escuela y poseyó 40 niños.

Los distritos y gobernaciones de Canta esperaron hasta los primeros años de la década de 1850, los últimos en los que gobernó Ramón Castilla, para que cada distrito contase con su propio gobernador, jueces de paz, así como síndicos procuradores. Pero lo que nos interesa resaltar es la instrucción y los alumnos allí existentes. El Calendario de 1852, descrito por el longevo sabio limeño, Eduardo Carrasco ${ }^{7}$, confirmó que ya en cada pueblo de los mencionados, se hallaba plenamente instalado un colegio de instrucción primaria. Señalaremos el número de alumnos registrados al ańo precitado, a saber:

- En Canta, se registraron 80 alumnos.

- En Pacaraos, 40,

- En Pasa, 32.

- En Arahuay, San Buaneventuray Huamantanga, treinta (30). Aunque no estamos tan seguros si se trataba de igual número para cada distrito, o que los tres sumaban treinta alumnos.

- En Lampián, 20, y, finalmente,

- En Pallac, 04.

La suma total de niños que recibieron la instrucción de primeras letras fueron de doscientos sesenta y seis (266), en toda la provincia. Ya se da por seguro que el método pedagógico que recibieron las referidas comunidades era el lancasteriano.

\subsection{Instrucción de primeras letras en el Callao y Chorrillos, 1827-1839}

Las primeras letras en el Callao. En torno al pago de de un preceptor, en 1829, el Estado peruano impuso a un tercero que del arrendamiento de una chacra en los alrededores de Lima por 50 pesos, y con ello el pago del sueldo del mencionado funcionario público. El arrendador dejó de pagar y el preceptor debió

7 CARRASCO, Eduardo. "Calendario y guía de forasteros de la República peruana, para el año bisiesto de 1852». Imprenta de Félix Moreno. Lima - Perú, 1851. Pág. 119. Por cierto, este hombre redactó El calendario y Guía de Forasteros de 1826, aunque en calidad de Cosmógrafo Mayor interino. Lo retomaría varios años después, ya como Cosmógrafo titular. Y anotamos que había ya ejercido como Cosmógrafo en los últimos años del período colonial. Carrasco nació en Lima en 1779, y falleció en la ciudad misma, en 1865 recurrir a las autoridades del Colegio Lancasteriano para que la dote estatal sea cumplida (AGNP; Real Justicia; 1830; LEG.75;) Observamos así que a las labores de la Dirección de instrucción primaria, no solo se encargaba de la organización y conducción de la preparación de maestros y preceptores, también fungió como representante de sus egresados ante el gobierno, en pos de la cancelación de sus pagos por las labores encomendadas. $\mathrm{Al}$ menos, en este particular caso, la solicitud hecha por un preceptor que está trabajando en el Callao, puerto central del Perú, y con las distancias muy próximas ante las principales instituciones públicas del Perú fue, relativamente, pronta en ser atendida.

Y ello por la insistencia de un joven egresado de la Escuela, quien solicitó una plaza como preceptor de primeras letras en el Puerto. Por cierto, no debemos generalizar este ejemplo, pues cada caso se desenvolvió en realidades distintas. Valga aquí mencionar la escuela pública de primeras letras a cargo del preceptor José Vicente Bustamante, fue la única y efectiva Escuela bajo el método Lancasteriano en ejercicio, al servicio de los niños y jóvenes del puerto del Callao. Sobre este personaje, Bustamante, nos ocuparemos en las siguientes líneas.

En 1827, el entonces ministro Vidaurre nombró verbalmente al Pbro. Francisco Garay como preceptor de primeras letras en el aula-escuela de San Lázaro, en Bellavista, Callao. Podemos ver aquí que el mencionado Garay tenía cercanías con personajes importantes de la política peruana. Sin embargo, en 1831 arribó el nuevo preceptor José Vicente. Este nuevo instructor, con la certificación del novedoso método, trajo consigo el aumento de párvulos en el aula, de cuarenta y dos (42) que asistían anteriormente, a los pocos ańos de su desempeńo lo elevó ochenta (80), y para comienzos de la década de 1830, a poco más de cien (100) párvulos. Obviamente esto empieza a originar confrontación con Garay. ¿Y quién era el precitado personaje? En el Calendario y guía de forasteros de 1828, preparado por Nicolás de Piérola, cosmógrafo interino de la república (PIÉROLA; 1827; P. 56). Se hallaba en la categoría de Maestro, y laboraba en la escuela sucursal de San Lázaro. Resultó tan loable, y de positiva acogida por la población local la función del nuevo preceptor en el Callo, que con el visto bueno del inspector Pbro. Antonio Camilo Guevara — regente titular de la prima de teología de la Pontificia Universidad San Marcos-, se le asignó un primer aumento de 42 pesos, llegando en 
1831 al monto de cincuenta pesos mensuales (50 ps.). En verdad, para la época es el un monto moderado y correcto, en comparación con los otros preceptores de provincia, inclusive aquí mismo en Lima. No sabemos cuál sería la fuente de procedencia de dicho monto, y si la misma se mantendría en el largo plazo. Sospechamos que fue solo un bono extraordinario.

Como lo hemos expuesto, José Vicente Bustamante, mantuvo correctas relaciones no solo con el Director de la Escuela Central, D. José Francisco, también contó con el apoyo y recomendación del catedrático Vergara, y ello no nos quepa duda que se trataba, principalmente, en relación a su correcto aprovechamiento académico, y logros laborales a vista de las autoridades, como de la población chalaca. Bustamante, en 1832 solicitó al Director General:

[...] Cantidad de ejemplares de discursos de JHS y parábolas de Salomón, siendo sobrantes de los que se repartieron a la Escuela de Santo Tomás, y como esta es gratuita como aquella, es de mi incumbencia ponerlo en consentimiento de usted, a fin que dando el derecho respectivo se me den 80 libritos de los primero, y 80 del segundo, por ser este el número de niños que pueden leerlos. (AGNP; Real Justicia; Ídem).

Y la respuesta de Director fue que no existía inconveniente alguno, que pase por el local de Santo Tomás para recoger su pedido. Este era el ejemplo de una estrecha relación entre la Escuela Central y sus egresados. Observamos que la Dirección, para la década de 1830 contaba ya con impresiones de discursos de JHS, así como de las parábolas de Salomón. Es innegable la referencia de quien fuera uno de los dos pilares de la formación lancasteriana, Diego Thompson. El otro fue el Pbro. José F. Navarrete. Y estamos convencidos que se trataba de pequeños opúsculos, más que textos propiamente.

El Estado no podía comprarlos, ello era correspondió a iniciativas particulares, o de casos muy concretos. El último rastro documental de D. José Vicente se halla en abril 1833, debido al éxito del aulaescuela de San Lázaro en el Callao, el nuevo Procurador decidió colocar a José Sierra, ahijado del procurador portuario, como preceptor de primeras letras allí. José Vicente cedió, y solicitó su traslado a otro centro educativo, uno que también se ubicaba en las cercanías del poblado de Bellavista. Creemos que ello sucedió antes de la presidencia de Orbegoso, en diciembre de ese año, en las postrimerías del controvertido gobierno de Gamarra y sus aliados. El mencionado señor José Sierra, natural de Trujillo, afirmaba haber aprendido el método Lancasteriano de uno de sus fundadores, allá en la ciudad capital, se refería a Diego Torres. Y quizá sea cierto, pues recordemos que Diego Thomson estuvo un tiempo radicando en el norte peruano, antes de su retiro definitivo hacia tierras ecuatorianas. Sobre el maestro Garay, a la postre, pidió a la Sociedad Filantrópica ser reubicado en algún otro Colegio, pedido que fue aceptado. En la guía de 1837, éste mismo Garay, ya no ejercía la docencia, lo encontramos laborando como funcionario de la Comisión creada para examinar la Deuda Externa Paredes; 1986; P.119). Pero ello, como lo vimos anteriormente, no era nada nuevo. En 1841, se registra a José Bustamante como un maestro lancasteriano, con su propia escuela, costeada por sus concurrentes. Su aula se ubicó en la céntrica, como exclusiva, calle limeña de Concha, con una concurrencia de cuarenta (40) estudiantes.

Estos aumentos selectivos para distintos casos, y seguramente para con distintos maestros y preceptores, sin olvidar que muchos de esos montos correspondían a la iniciativa de las familias y habitantes del lugar para que se continuase con la instrucción de sus menores, empezaron a traer problemas al fisco. En este caso particular, al gobierno del Callao, en ese tiempo ubicado dentro de la Fortaleza del Real Felipe. Llegó a los despachos de las autoridades locales el oficio de un profesor de primeras letras, quien laboraba en las cercanías de la Hacienda Bocanegra —en ningún momento dicho individuo menciona en su defensa, como conocedor del o Lancasteriano-, quien al enterarse del aumento en cuarenta y tantos pesos de José Vicente, también desea su mejora económica: «[...] El sueldo de 30 ps., que percibo del estado, y que sale de la Dirección de Consolidación no es suficiente [...]» (AGNP; Real Justicia; Ídem)

Hasta ese momento, el sueldo de los preceptores estaba saliendo del ramo Dirección de Consolidación, pero esta Dirección fue extinguida en 1828, y la responsabilidad de la viabilidad y de las cancelaciones de pagos pendientes de los maestros, corrió en gran medida por la Beneficencia. Tal es la real problemática que enfrentan los maestros y preceptores en torno a la excesiva tardanza en la cancelación por sus servicios. Pero en estos episodios históricos, lamentablemente entra a tallar también la insania y el excesivo interés por sí mismo, y por la pandilla de compañeros de 
rapiña, más que por los reales intereses de quienes sirven al Estado en sus labores más esenciales, como lo era la instrucción de la ciudadanía. En verdad observo con aflicción, aún a la distancia del tiempo, el maltrato hacia los maestros, sus petitorios eran de justicia, y sus necesidades debieron ser cubiertas con mayor prontitud. Así que en agosto de 1829 se eleva al prefecto de Lima, Juan bautista Eléspuru, destacado partidario de Gamarra, que haga cumplir una nueva ley en la que: «[...] Cada casa de juegos de Lotería de cartones, abone a algún ramo de Fomento de algunas Escuelas de Instrucción de Primeras Letras, la suma de 25 ps». (AGNP; Real Justicia; Ídem).

Como podemos observar, el otrora pueblo de indios colonial del puerto del Callao, empezó a tomar con mayor receptividad y expectativa la labor de los preceptores en primeras letras. Y hubo fluida comunicación con la Escuela Normal de Santo Tomás. Sus maestros egresados gozaron de un sueldo de 50 pesos mensual, notorio contraste con lo que ganaban los maestros en las provincias alejadas de la ciudad. Otro caso particular es el registrado en la Escuela de Bellavista, donde su maestro inició sus labores ganando treinta pesos (30 ps.), y ello originó el reclamo de este maestro, Manuel Larenas, también egresado de la Escuela Lancasteriana. Esta vez, dirigido hacia el prefecto de la provincia. ¿Esa era la estrategia para un progresivo aumento de sueldo? A su vez, éste lo elevaba al Supremo Gobierno. Pero a veces los resultados no nos salen como esperábamos. En 1828, luego de la nefasta traición de Gamarra y La Fuente hacia el Presidente electo La Mar, el encargado del despacho, en esta ocasión, Justo Figuerola, respondió lo siguiente: «No permitiendo por ahora los fondos públicos aumentar la dotación, si el escolero [sic] no se conforma con ella, lo licítese otro por medio de la inspección de instrucción pública». (AGNP; Fondo de Instrucción; 1828; S/F).

Las primeras letras en Chorrillos. Chorrillos tiene pautas comunes con la historia de la ciudad capital misma. Durante la reconstrucción del puente entre el arrabal de San Lázaro y la ciudad, el virrey Marqués de Montes Claros (virrey entre 1607 y 1615), ordenó su construcción con mampostería y base de piedra sillar, proveniente de «Los Chorrillos». Desde la época colonial, el pueblo de Chorrillos, poblado en su mayoría por indios, servía como caleta, o puerto menor, recibiendo navíos de poco tonelaje, generalmente provenientes de Pisco. Desde tiempos coloniales también, era de reconocimiento público el Tambo de Chorrillos, muy transitado pues era parte del camino real colonial, hacia el sur, como hacia la ciudad capital. Dicha labor continuó en también durante el período republicano. Durante el desarrollo del siglo XIX, siguiendo a Jorge Lossio, el pueblo de Chorrillos, así como sus tierras y chacras de cultivo, formó parte de un "cinturón agrícola», que favoreció si bien en la relativa cercanía por la obtención del panllevar a la población, también la sobreexpuso a la infección y expansión en la ciudad de las enfermedades tropicales. A saber:

En las inmediaciones de la ciudad se ubicaban las lomas de San Juan y Monterrico, las pampas de Amancaes, los balnearios de Chorrillos y Miraflores, las haciendas de la Magdalena Vieja y de Surco, y los valles de Ate, Carabayllo y Lurigancho. Es decir, la ciudad estaba franqueada por un cinturón agrícola, un cinturón «verde». Ello le permitía conseguir recursos alimenticios, pero también la exponía a amenazas ambientales. (Lossio; 2003; P. 23).

El almanaque de 1826 (Carrasco 1825: p. 69) ${ }^{8}$, ya registraba a Chorrillos como una Oficina de Tenencia de Administración, dependiente de la Aduana de Lima. Para ese año se encontraba al teniente coronel de caballería, en retiro, Martín Herrero, como Administrador principal, y como oficiales a Mariano Gómez, Francisco Xavier Jordán y Armando Montes. Asimismo, las fuerzas militares acantonadas, seguramente en número austero, se hallaron ese año bajo las órdenes del Capitán de Fragata, Jorge Young. En 1839, el 28 de enero a las 03 de la mañana9 ${ }^{9}$ la ciudad de Lima sintió un fuerte terremoto, narrado en las crónicas de la época, los Almanaques, diarios de viajeros, entre otras fuentes. A la violenta sacudida de la capa terrestre, le sucedieron gruesas lluvias (en una ciudad acostumbrada a la garúa), sobrecargando algunos canales y acequias, y amaneciendo las calles mojadas de agua turbia y «colorada». En el pueblo de Chorrillos, como en todas las zonas aledañas a la ciudad, en horas de la madrugada, tres y media aproximadamente $(3.30 \mathrm{am})$, junto con la inusual lluvia, y ya consecuencia de la cada vez más recia fuerza de los vientos, el mar empezó a picarse. Una ola de frío que empezó a atemorizar a la población, se empezaba a extrañar un frente climático de frío, obligando a los

8 En este año, por cierto, ya se le empezaba a describir a Chorrillos, como
uno de los distritos de Lima. 9 Paredes... Pág. 42 
habitantes, sobre todo los de Chorrillos, a suspender los baños, y, curiosamente, a salir con abrigos y mantos a las calles. Dicho fenómeno climático continuó aún algunos días más.

Retornando a las primeras letras, en este pueblo, la Escuela lancasteriana fue solventada directamente por los ingresos del arriendo de los Tambos de Chorrillos y de Surco ${ }^{10}$, siendo ambos de licencia pública para su administración. La cantidad de pago era variante, para el ańo de 1828, el monto de pago fue de cuarenta pesos (40 ps.) Para dicho año, el nuevo arrendatario, Francisco Ruiz, respondió a la inicial solitud del impuesto en pos del funcionamiento y continuidad de la escuela de primeras letras del lugar. Asumió la solicitud, dicho año al menos, como una temporada aciaga para los negocios: "Una aminoración en las ventas en el tiempo actual de invierno, por la ausencia de peruanos al Callao». (AGNP; Fondo de Instrucción; 1828; S/F)

$\mathrm{Su}$ petitorio fue rechazado a los pocos días, así constó en el registro documental, por las autoridades locales: tanto del Alcalde de dicho pueblo, D. Josef Samudio, como de cuatro regidores mayores del mismo, Juan de la Rosa Luezero, Matías Garcés, José María Samudio y Josef Miranda; refrendado por el Secretario de Cabildo, Manuel Huapaya. Lo si bien nos mostró el interés que despertaron las primeras letras entre los centros poblados circundantes a la ciudad capital, nos expuso también la enorme influencia política de los mercaderes de los tambos de Lima. El arrendatario oficial del Tambo, Francisco Ruíz, entonces cambió de discurso, giró su estrategia. Aceptaba el monto respectivo, pero exigió la rebaja del pago de su arriendo de su tambo: «Las ventas son reducidas a juntas, y otras cosas que no se merecen, y sobre todo en cantidades muy pequeñas $[\ldots] »$. (Ítem). Y en esta ocasión, su enfrentamiento ante el alcalde de Chorrillos y su junta fue más frontal. Los mismos, refutaron su propuesta, ahora con mayor consistencia, empezó un tira y afloje entre el arrendatario, el alcalde y los fiscos declarados, así como algunos otros no declarados.

Para la década de 1830 estaba muy bien consolidado en la ciudad el Protomedicato, una institución que si bien de origen y emparentado académicamente con

10 Los tambos, en especial los mencionados, hasta avanzado el siglo XIX, representaron interesantes ingresos a las arcas municipales. Funcionaban, salvando las distancias a lo que hoy podríamos llamar mercados de abastos. La administración del Tambo corría por un solo intermediario, nombrado por el Cabildo. la Universidad, y la práctica de la medicina, en la etapa republicana se le asignó cada vez más, funciones de control de salud y enfermedades en favor de la población de la ciudad. La junta municipal expuso un contundente argumento: «Aun en cantidades muy pequeñas que no pueden compararse con lo que abraza el tambo en que aún se expenden drogas de botica que nadie mantiene $[\ldots . .$. ». (ÍTEM).

Si el arrendatario insistía en no pagar la contribución extraordinaria de diez pesos (10 ps.) en pos de que con dicho monto se pagase al instructor lancasteriano, entonces el trámite le iba a ser, progresivamente, de mayor pleito ya no solo con el cabildo local, el panorama amenazaba con la intromisión del Protomedicato, pues el astuto comerciante lo pretendía descontar del impuesto que pagaba a dicha institución médica pública. El monto de cuarenta pesos (40 ps.), que se procuraba imputar al arrendatario del tambo de Chorrillos, se convirtió ya en serio problema político, había sido elevado al Supremo Gobierno. Las autoridades locales ahora cabildeaban ante el mismo Ministro de Estado. Mencionaron otra vez lo perjudicial que resultaba el monto que se venía pagando, desde tiempos antes al final de la opresión española [sic]. Para la comunidad, la instrucción representó ya su más ferviente deseo, y deseaban costear las escuelas de primeras letras, $y$ de cuyo beneficio no podía privarse a la juventud. A colofón de este pleito, el Ministro de Estado de ese año, otra vez Justo Figuerola, no le hizo gran favor al pueblo de Chorrillos. Los cuarenta pesos ( 40 ps.), se mantuvieron, pero ya no fue diez pesos (10 ps.) el descuento, sino veinte $(20$ ps.) pero en desmedro de lo que recibía el pueblo por el arriendo del Tambo.

\section{El decreto supremo del 28 de febrero de 1840}

Un avance político en la autonomía del manejo económico de las primeras letras, fue alcanzado durante el año de 1840, durante el gobierno del presidente Agustín Gamarra. La definitiva separación del presupuesto del ramo, que aún para esa fecha dependió -aunque cabe decirlo, con bastante potestad en sus rentas- aún de la Junta de Beneficencia. Los fondos a partir de la emisión del decreto, correspondían exclusivamente hacia los gastos y haberes de los colegios, como de la instrucción primaria. Este decreto obligó a la Junta de Beneficencia entregar a la Dirección General los margesíes, razón de deudas, y demás documentos 
MAPA DE LA UBICACIÓN APROXIMADA DEL TAMBO REAL DE CHORRILLOS, S. XIX

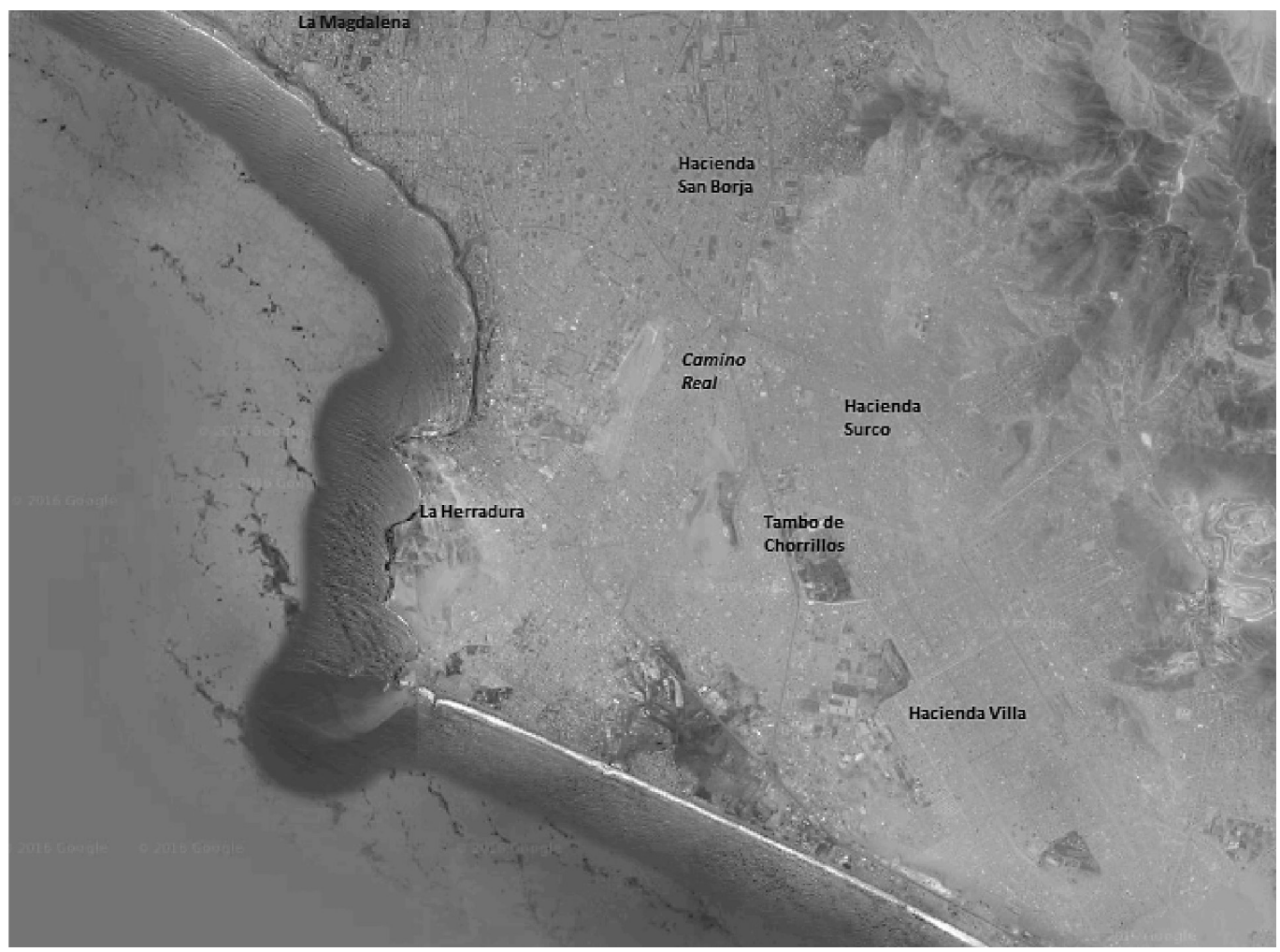

Fuente: Google Maps. Alphabet INC. DR. 2016.

*** Las ubicaciones aproximadas de las haciendas del siglo XIX, son de aporte de nuestra autoría. correspondientes para su mejor manejo. Se creó una Junta Administradora, inseparablemente unida a la Dirección General de Instrucción. Esta junta estaba incluida por:

- Los rectores de los colegios, léase públicos.

- Directores de las Escuelas Centrales de instrucción.

- Un representante del Prefecto.

Cada seis (06) meses esta Junta debía presentar cuenta documentada de sus ingresos y egresos al Prefecto, quien lo elevaría al Supremo Gobierno, para su aprobación o devolución, levantando las observaciones que en ella se encontrasen. Sin embargo, ahora el poder se concentró en el Prefecto, quien -a decisión y criterio personal- ejerció el derecho de censura, veto y suspensión de los miembros de la junta. Durante el gobierno de Gamarra, ejercieron, como Ministro de Instrucción Pública, Beneficencia y Negocios Eclesiásticos, el Pbro. Agustín Guillermo Charún (12 años después sería preconizado como Obispo de Trujillo); como Oficial Mayor del ramo, a José Dávila Condemarín (quien en 1854 alcanzó el rectorado de la Pontificia Universidad de San Marcos). Ese mismo año, Charún ejercía de rector del Convictorio Carolino.

\section{Un epílogo inconcluso}

La Independencia no trajo consigo una ruptura inmediata entre las funciones de un Estado colonial, y su reemplazo, un Estado republicano. La función educativa pública que cumplió, insuficientemente por cierto, el Estado colonial, fue asumida inmediatamente por el Estado Republicano. Prueba de ello representan las series documentales de la época, emitidas desde distintas instancias y niveles de alcance del Gobierno de turno. La Dirección de la Escuela Normal de Santo Tomás lo ejerció ese año Mariano Idalgo [sic], con una concurrencia estudiantil de más de doscientos niños y jóvenes. La escuela sucursal de San Lázaro, bajo la dirección de Fernando Riega, poco más del mismo número (Carrasco; 1840; P. 39]. La escuela de Santa Teresa, con su directora Eusebia Morales, poco más doscientos también. Si bien los números son redondos, ello significa, a nuestro criterio, un logro deseado y anhelado alcanzado por la ciudadanía de la capital. La instrucción de primeras letras empezó, recién a mediados de 1850 , a ser un invitado común entre las diversas instituciones existentes en la capital. Los niños ahora tenían un nuevo espacio, el de ser instruidos, el de saber leer y escribir. Una nueva oportunidad. Las 
familias limeńas empezaron a tener clara conciencia del rol de la educación, les ofrecía trabajo remunerado, una mejora ostensible en sus condiciones de vida. Progresivamente, los presbíteros y párrocos iban cediendo espacios, como naturalmente se esperaba, a los jóvenes preceptores y maestros egresados de la Escuela Normal.

Pero el camino hacia la instrucción plena hacia la enorme geografía de la republica peruana, recién comenzaba. Ahora sí, la oportunidad económica que representó la bonanza del guano, permitió un ejército de jóvenes preceptores y maestros lancasterianos en la cantidad suficiente, para enviarlos a los diversos puntos geográficos del país. Algunos colegas hablan de necesidades ciudadanas, particularmente pensamos que fueron más por necesidades básicas, el motivo esencial que promovieron los padres de familia al insistir en la instrucción de sus menores hijos. Desearon brindarle espacios laborales que a ellos no les correspondió ejercer. Que hayan existido excepciones, por supuesto, pero son los casos que, justamente, confirman la regla. El nuevo camino estaba por empezar.

\section{Repositorios de investigación histórica}

- Archivo General de la Nación Peruana, Lima.

- Real Justicia, s. XIX.; Fondo de instrucción 1820-1850.

- Archivo virtual de la Legislación Peruana.

- Administrada por el Congreso Nacional del Perú.

\section{Referencias documentales}

Carrasco, E. (1840). Calendario y guía de forasteros de Lima para el año de 1841. Lima: Imprenta de Félix Moreno.

Paredes, J. G. (1821). Calendario y guía de forasteros de Lima, para el año bisiesto de 1828. Lima: Imprenta del Estado.

Piérola, N. (1827). Calendario y guía de forasteros de Lima, para el año bisiesto de 1828. Lima: Imprenta de la Instrucción Primaria.

S/A (1833). Manifiesto que la mayoría de la M. H. J. Del D. de Lima presenta al público imparcial sobre las ocurrencias del último periodo de sus sesiones. Lima: Imprenta J. M. Del Castillo.

\section{Referencias bibliográficas}

Acuerdo Nacional. (2016). Políticas de Estado y planes de gobierno, 2016-2021. Lima: Secretaría ejecutiva del Acuerdo Nacional.

Durkheim, E. (1975). Educación y sociología. Barcelona: Ediciones Península.

Huaraj, J. (2017). Estado, sociedad y educación en el Perú: la instrucción de las primeras letras en lima, 1821-1850. Tesis de grado no publicada de Maestría en Historia. UNMSM. Unidad de Posgrado de la Facultad de Ciencias Sociales. Lima, Perú.

Huaraj, J. (2006). La instrucción de primeras letras en las provincias de Lima: 1821-1840. Revista de Investigaciones Históricas - Uku Pacha. Año 05. N 10. 89-93

León, D. T. (2008). Evangelización y control social de la doctrina de Canta. Siglos XVI y XVII. Tesis de grado de Maestría. UNMSM. Unidad de Posgrado de la Facultad de Ciencias Sociales. Lima, Perú.

Lossio, J. (2003). Acequias y gallinazos. Salud ambiental en Lima del siglo XIX. Colección Mínima. № 55. Lima: IEP. 